\title{
Women's Representation in Federal Transportation Agencies: A Descriptive Analysis
}

\author{
Behzad Rouhanizadeh ${ }^{1}$, Amirhosein Jafari ${ }^{2}$ and Sharareh Kermanshachi ${ }^{3}$
}

1 University of Texas at Arlington, Arlington, USA, behzad.rouhanizadeh@mavs.uta.edu

2 Louisiana State University, Baton Rouge, USA, ajafari1@lsu.edu

3 University of Texas at Arlington, Arlington, USA, sharareh.kermanshachi@uta.edu

\begin{abstract}
Gender inequality in engineering career fields has been a source of social and economic disturbances for many years. In several cases, women are underrepresented, and disparities persist despite policies that have focused on initiatives to promote gender equality in the industry, and the inadequacy of tools for measuring and analyzing the imbalance confounds the problem. This study investigates women's underrepresentation in engineering careers from 2011-2017, by aggregating data from 17,889 demographic profiles of the U.S. Department of Transportation (USDOT) workforce. The objective of the study was to perform a descriptive analysis to (1) explore women's representation in the USDOT, and (2) discover the factors that can reduce or eliminate the low representation of female engineers and if there is any wage gap that exists between the genders. This includes the impact of factors such as job location, education level, type of appointment, job position and its importance, level of experience, and supervisory role of the employee. According to the outputs, women hold fewer high-level positions than men in the USDOT, but no significant gender-related wage inequality exists. The findings can help public and private organizations design legislative initiatives to achieve greater gender equality and assist employers of engineering organizations in moving toward a more gender-diverse working environment to reduce or eliminate gender inequality and its consequent challenges.
\end{abstract}

(c) 2020 The Authors. Published by Budapest University of Technology and Economics \& Diamond Congress Ltd Peer-review under responsibility of the Scientific Committee of the Creative Construction Conference 2020.

Keywords: women, underrepresentation, USDOT, transportation agencies, workforce, wage rate

\section{Introduction}

Today's worldwide economy is driven to a large degree by advancing technology and provides opportunities for women to pursue education and careers in fields, including engineering, that have been historically dominated by men. Women were much more limited in their choice of a career in the past, but for the last several decades, they have assumed important roles in most socioeconomic activities $[1,2]$. Women are now hired for many of the positions previously filled exclusively by men [3,4]; however, underrepresentation of women in engineering fields still remains an issue that leads to adverse socioeconomic consequences [5] and discourages women from pursuing engineering careers [4]. Education level, experience, efficiency, gender discrimination, etc. are also factors that contribute to women's underrepresentation in engineering.

Several scholars have conducted studies on gender inequalities in engineering fields. Beaton et al. [6] indicated that there is a direct relationship between the underrepresentation of women and their unwillingness to pursue an engineering career. Hunt [7] identified discrimination by male peers as an important reason why women engineers exit engineering fields. Infante-Perea et al. [8] revealed that while pursuing an engineering career, women often face gender-related barriers and discrimination that prevent 
them from actually entering the field. They also identified lack of confidence and self-esteem as obstacles for women in occupying higher level engineering positions.

Despite research into women's underrepresentation in engineering fields, disparities still exist between women and men [9]. To resolve this issue, it is important to measure and analyze the factors that contribute to the problem. The goal of this research was to (1) explore the current status of women's representation in transportation related engineering careers, and (2) discover the factors that can reduce or eliminate this challenge. This research will assist employers of engineering agencies in creating more gender-diverse working environments that will result in reducing and/or eliminating gender inequality and the consequent challenges in their organizations.

\section{Literature review}

Rapid changes in technology in the past several decades have made engineering occupations more attainable for individuals of any gender $[10,11]$ even though traditionally, the inherent activities such as design, field work, etc., have been perceived as masculine occupations [12]. Despite the claim by some that gender inequalities and women's underrepresentation in engineering fields have declined, there is still a gap [13]. In the US, for instance, only $15 \%$ of those in the engineering sector are women [14]. Since more women are pursuing an engineering career today than they did decades ago, an accurate analysis of the factors that lead to women being underrepresented is needed $[15,16]$.

Various efforts have been attempted to decrease women's underrepresentation in the engineering fields. Women have been encouraged to pursue an education that would equip them for the engineering professions [9], and initiatives such as the Packard Scholars Program have been offered to motivate them $[17,18]$ and to improve the public's perception of women in what has been a male-dominated field $[9,16]$. Research and activities have been conducted to determine the factors that have led to female underrepresentation, and one of the earlier ones concluded that it is a result of social beliefs about genderrelated roles that are established in childhood and continue into adulthood [19]. However, Galy-Badenas [20] showed that the recent technological advancements have led women to achieve higher education levels and consequently have changed the general social beliefs and behaviors about women's social roles and abilities. Burke [21] identified several factors, including diverting high school girls from math courses because they were perceived as being too difficult for them. Wang et al. [22] investigated the relationship between women's educational pathways and their success in engineering fields and revealed that selfefficiency was a significant motivating factor for better representation in engineering. In addition, race and marital status were identified as potential barriers for women that resulted in their not pursuing engineering professions [22]. Karimian et al. [23] developed a framework identifying the employees at risk of wage inequality and demonstrated that women working in engineering sectors are at risk of wage inequality.

Notwithstanding the efforts that were made to decrease the gender inequalities, women still encounter obstacles and challenges to becoming engineers and surviving in the workforce $[24,25]$. Balamuralithara et al. [26] indicated that many engineering companies/organizations and their male workforce do not consider women capable of performing difficult engineering tasks, especially in higher level positions. Mahajan and Golahit $[27,28]$ also revealed that the competitive and objective qualities required for obtaining higher wages and positions in engineering organizations are perceived as being masculine, which leads women engineers to underestimate their capabilities in competing with men. Myers [29] says that it is this stereotypical behavior that prevents women from climbing the proverbial career ladder. Foust-Cummings et al. [30] showed that the lack of role models, mentors, and sponsors for women employed in engineering fields impedes their progress.

In summary, there is an increasing demand in engineering fields that makes the involvement of women important and the elimination of the underrepresentation necessary. The inequalities between men and women have decreased during the past few decades, but they are still male-dominated. An accurate analysis of the impeding factors should be performed to resolve this issue [30,31]. 


\section{Methodology}

This study aimed to investigate the representation of women employees in USDOT, using descriptive analysis. Demographic data of the skilled labor in the USDOT from 2011-2017 was used, which included 17,889 USDOT employees. The following variables were used:

(1) The gender variable is a categorical variable based on two values: male and female.

(2) The salary range variable is a categorical nominal variable based on six values: under $\$ 30 \mathrm{~K}, \$ 30 \mathrm{~K}$ to $\$ 49 \mathrm{~K}, \$ 50 \mathrm{~K}$ to $\$ 69 \mathrm{~K}, \$ 70 \mathrm{~K}$ to $\$ 89 \mathrm{~K}, \$ 90 \mathrm{~K}$ to $\$ 109 \mathrm{~K}$, and over $\$ 109 \mathrm{~K}$ per year.

(3) The age range variable is a categorical nominal variable based on nine values: under 25, 25-29, 3034, 35-39, 40-44, 45-49, 50-54, 55-59, and 60 or higher.

(4) The education level variable is a categorical nominal variable based on four values: high school degree or less, college with no bachelor's degree, bachelor's or post-bachelor's degree, and graduate or professional degree.

(5) The years of service variable is a categorical nominal variable based on eight values: under 4 years, 5 to 9 years, 10 to 14 years, 15 to 19 years, 20 to 24 years, 25 to 29 years, 30 to 34 years, and over 35 years.

(6) The job position variable is a categorical variable based on nine values: community planning, contracting, engineering, financial management, human resources professional, information technology, Non-MCO, transportation safety, and transportation specialist.

(7) The fiscal year variable, which represents the year that the employee is hired, is a categorical nominal variable based on seven values: from 2011 to 2017.

Two primary indexes were used in this study to investigate women's representation, including (i) the total number of female employees, and (ii) the ratio of female to male employees. The impact of factors such as salary range, education level, job position, and the level of experience on gender representation was investigated. Six null hypotheses are shown in Table 1. A statistical analysis, called the likelihood-ratio test (LRT), was used to test the goodness-of-fit between the ratio of female to male employees and other factors, based on each null hypothesis. The likelihood-ratio test rejects the null hypothesis if the P-value is smaller than 0.01 (significance level of 1\%). A statistical software called JMP was used to perform LRT (JMP 2019). JMP software is partly focused on exploratory data analysis and visualization. It was designed for users to investigate data to learn the unexpected, as opposed to confirming a hypothesis.

Table 1. The null hypotheses tested in this study

\begin{tabular}{cl}
\hline No & Null Hypothesis \\
\hline 1 & There is no significant correlation between female to male employees ratio and the year of employment \\
\hline 2 & There is no significant correlation between female to male employees ratio and the age of employees \\
\hline 3 & There is no significant correlation between female to male employees ratio and the salary range \\
\hline 4 & There is no significant correlation between female to male employees ratio and the job positions \\
\hline 5 & There is no significant correlation between female to male employees ratio and the education level \\
\hline 6 & There is no significant correlation between female to male employees ratio and the experience level \\
\hline
\end{tabular}

\section{Results and discussion}

\subsection{Women's representation}

The trend of female employee numbers and their proportion to male employees was explored for different years at USDOT. Among the 17,889 employees studied, only 4,286 were females (24\%); the ratio of female to male employees was $32 \%$. Fig. 1.a shows the trend of employment for each year, based on the gender of the employees, and illustrates that except in 2013, when there was a decrease, the number of employees at USDOT (both male and female) increased every year. Fig. 1.b shows the ratio of female to male employees each year and illustrates that although there was a decrease in the total number of employments and accordingly a decrease in the number of female employments in 2013, the ratio of female to male employees was at the highest (36\%). A year later, however, in 2014 , this ratio was at the lowest (28\%). A likelihood-ratio test was used to test whether there was a statistically significant correlation between the female to male employee ratio and the year of employment (null hypothesis \#1). It resulted in a P-value of 0.0965 , which cannot reject the null hypothesis; therefore, no statistical evidence was found that women's representation changed. 


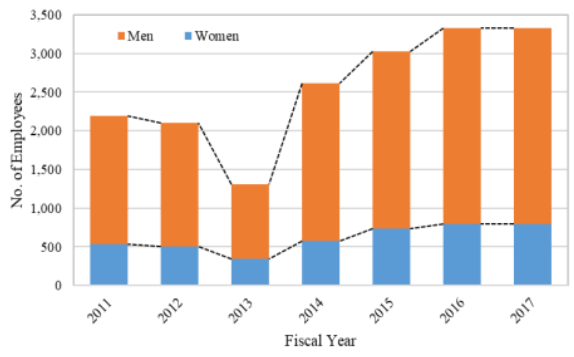

a. Number of employees in different years

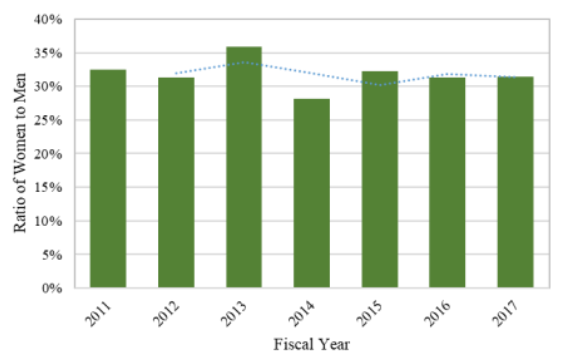

b. Female to male employees ratio in different years

Fig. 1. Female representation in different years at USDOT

Fig. 2.a shows the number of employees based on gender for each age range and illustrates that except for the age group under 25 , there were more jobs at USDOT for younger employees of both genders. Fig. 2.b shows that the ratio of female to male employees was higher than average from ages 35 to 59, with the highest (42\%) for the age range of 35 to 39 years old. This ratio was smaller than average for those under 34 years old and 60 years old and higher. A likelihood-ratio test was used to test whether there was a statistically significant correlation between the female to male employee ratio and the year of employment (null hypothesis \#2). It resulted in a P-value of $<0.0001$, which rejects the null hypothesis. Therefore, there is statistical evidence to prove that women's representation has changed regarding the age of employees. In general, it can be concluded that there is greater representation of women in older employees.

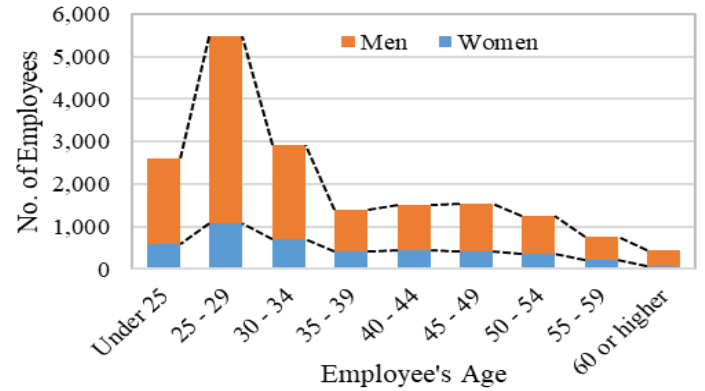

a. Number of employees in different ages

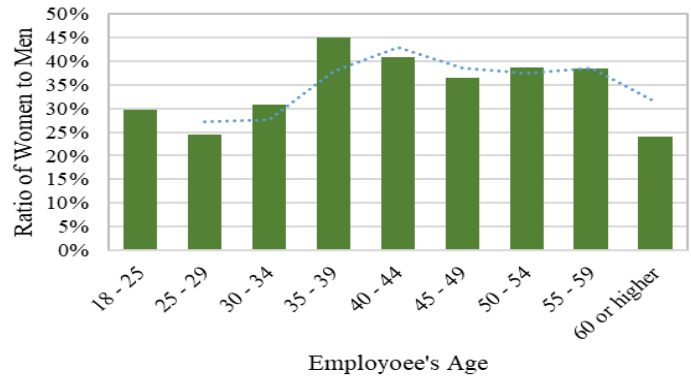

b. Female to male employees ratio in different ages

Fig. 2. Female representation in different age range at USDOT

\subsection{Women's salary}

The salaries of the female employees at USDOT were explored. Fig. 3.a shows the number of employees based on their salary range, and illustrates that the number of female employees with higher salaries was smaller than the number of female employees with lower salaries. It was almost the same for male employees, except for the $\$ 30 \mathrm{~K}$ to $\$ 49 \mathrm{~K}$ salary range. Fig. 3.b shows the ratio of female to male employees in each salary range and illustrates that except for the salary range of $\$ 30 \mathrm{~K}$ to $\$ 49 \mathrm{~K}$, which unexpectedly had a lower number of male employees and so a higher ratio of female to male employees, this ratio usually increased with an increase in the salary range.

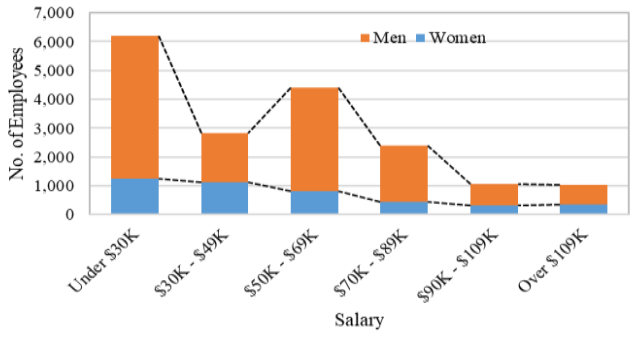

a. Number of employees with different salary

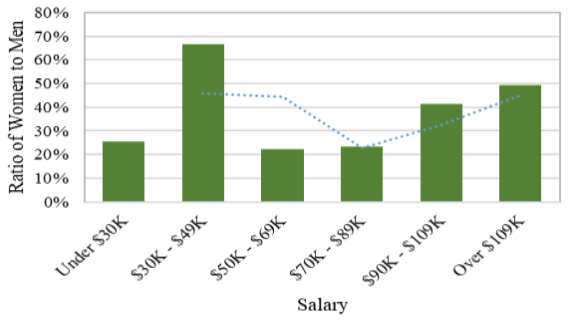

b. Female to male employees ratio in different salary

Fig. 3. Female representation in different salary range at USDOT 
For the salary range of over $\$ 109 \mathrm{~K}$, this ratio was as high as $50 \%$. A likelihood-ratio test was used to test whether there is a statistically significant correlation between the female to male employee ratio and the salary range (null hypothesis \#3). It resulted in a P-value of $<0.0001$, which rejects the null hypothesis. Therefore, there is statistical evidence to prove that women's representation has changed regarding the employee's salary range. In general, it can be concluded that there are more women in jobs with higher salaries. In addition, the trend of female employee numbers and their proportion to male employees was explored for different years and different salary ranges at USDOT.

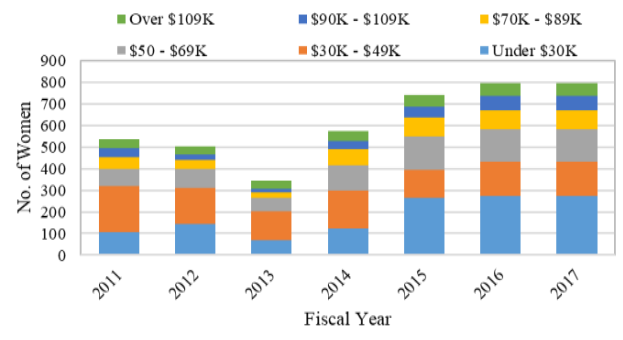

a. \# of female employees in different years and in different salary range

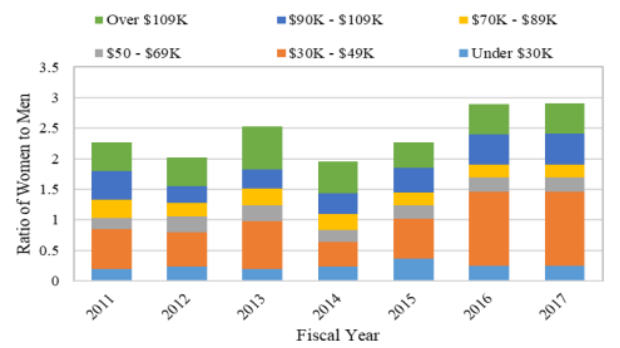

b. Female to male ratio in different years and different salary range

Fig. 4. Female representation in different years with different salary ranges at USDOT

Fig. 4.a shows the trend of female employees for each year and in each salary range. The figure illustrates that in recent years, more female employees with salaries under $\$ 30 \mathrm{~K}$ or over $\$ 90 \mathrm{~K}$ were hired at USDOT than with average salary ranges. Fig. 4.b shows the ratio of female to male employees for each year and each salary range, and illustrates that more women earned salaries of $\$ 30 \mathrm{~K}$ to $\$ 49 \mathrm{~K}$ almost every year. The trend of the USDOT number of female employees and their proportion to male employees was explored for the different age groups and years. Fig. 5.a shows the trend of female employees for each year and in each salary range, and illustrates that younger female employees usually have the lower-salaried positions. Fig. 5.b shows the ratio of female to male employees for each year and with different age ranges, and illustrates that the ratio of younger females to younger male employees was higher in jobs with higher salary ranges. As an example, although the salary range of $\$ 30 \mathrm{k}$ to $\$ 49 \mathrm{~K}$ had the highest ratio of female to male employees, for the employees aged of 25 to 34 years old, this ratio approached $100 \%$ for employees with a salary over $\$ 109 \mathrm{~K}$.

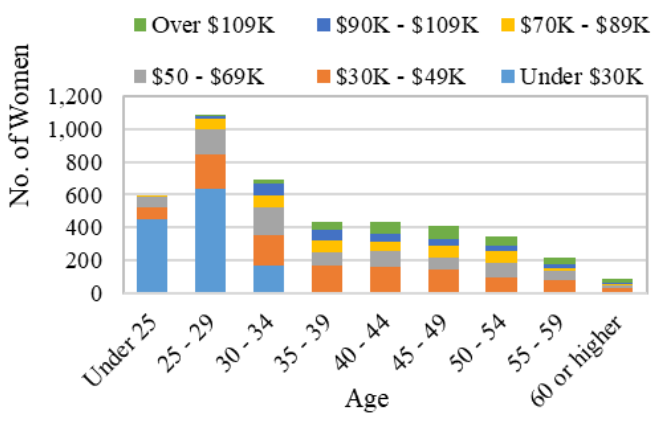

a. \# of female employees in different years and with different ages

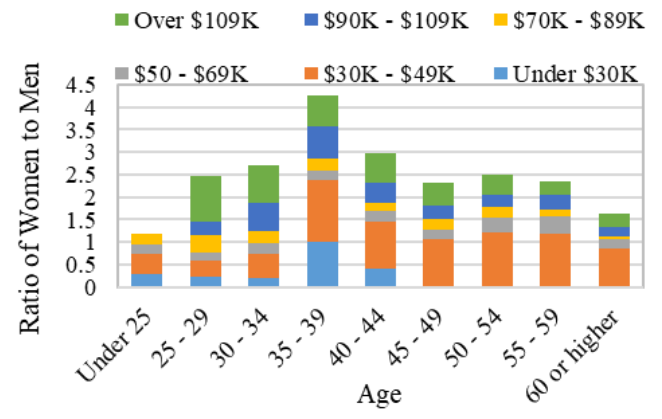

b. Female to male ratio in in different years and with different ages

Fig. 5. Female representation in different years with different ages at USDOT

\subsection{Women's job positions}

In this section, the job position of female employees at USDOT is explored. Fig. 6.a shows the number of employees based on their job positions and illustrates that $94 \%$ of the employees had one of three jobs: transportation safety, non-MCO (not related to mission-critical occupation engineering family), and engineering. The job position of non-MCO had the highest number of female employees (48\%), while transportation safety had the highest number of male employees (60\%). Fig. 6.b shows the ratio of female to male employees for each job position. 


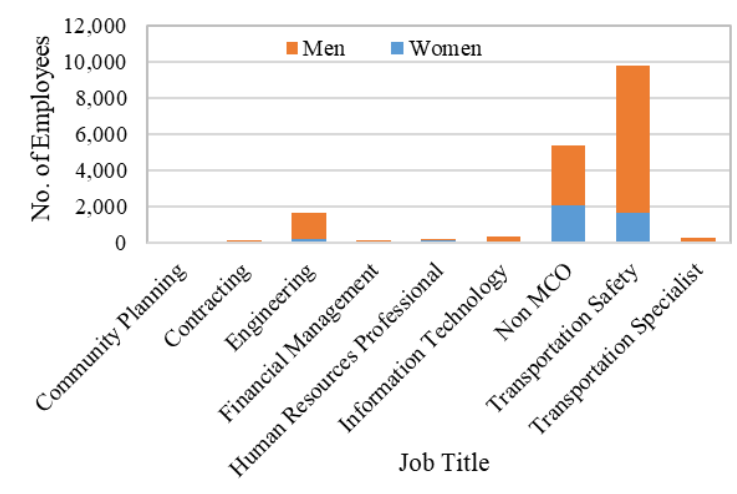

a. Number of employees in job positions

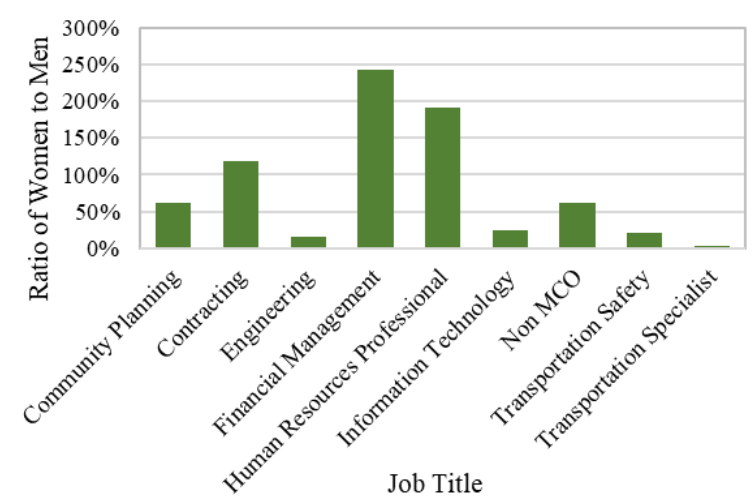

b. Female to male employees ratio in job positions

Fig. 6. Female representation in different job positions at USDOT

Although there were a large number of female employees in transportation safety, non-MCO, and engineering positions, the ratio of female to male employees was extremely low in these positions $(0.20$, 0.62 , and 0.15 , respectively) because of the high number of male employees. On the other hand, the very high ratio in financial management (2.43) and human resource professional (1.90) illustrates the large number of women in those job positions. A likelihood-ratio test was used to test whether there is a statistically significant correlation between female to male employee ratio and job positions (null hypothesis \#4). It resulted in a P-value of $<0.0001$, which, as was expected, rejects the null hypothesis. Therefore, there is statistical evidence to prove that women's representation has changed in different job positions. In general, it can be concluded that more women hold positions in financial management, human resources, and contracting. Fig. 7.a shows the trend of female employees for each year and in each job position, and illustrates that in recent years, more female employees have been hired in transportation safety, non-MCO, and engineering positions. Fig. 7.b shows the ratio of female to male employees for each year and each job position, and illustrates that in recent years, the ratio of female to male employees was higher in human resource professional and contracting positions.

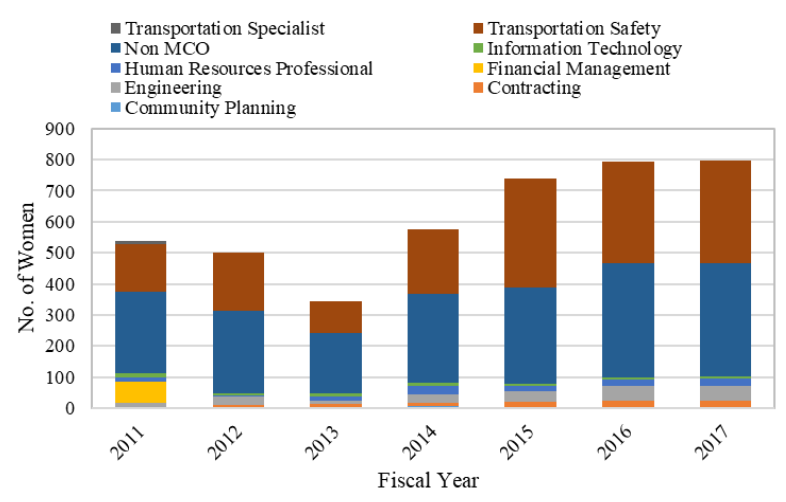

a. \# of female employees in different years and in different job positions

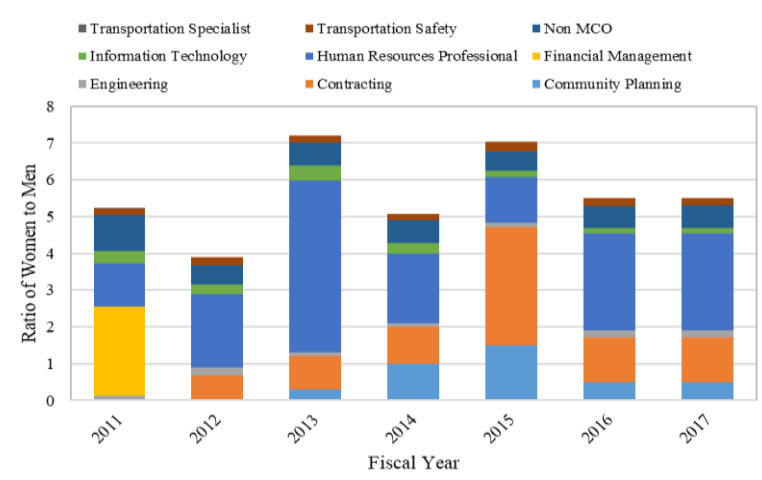

b. Female to male ratio in different years and in different job positions

Fig. 7. Female representation in different job positions in different years at USDOT

The trend of the number of female employees and their proportion to male employees was explored for different job positions with different salary ranges at USDOT. Fig 8.a shows the trend of female employees in each job position and each salary range, and illustrates that most of the female employees working in transportation safety had a salary under $\$ 30 \mathrm{~K}$, most of the female employees working in financial management had a salary range of $\$ 30 \mathrm{~K}$ to $\$ 49 \mathrm{~K}$, and the female employees with a salary range of over $\$ 109 \mathrm{~K}$ usually worked in information technology, contracting, or human resource professional positions. Fig. 8.b shows the ratio of female to male employees for each year and each job position, and illustrates that human resource professionals in higher salary ranges have higher ratios, as do those in financial management positions in lower salary ranges. 


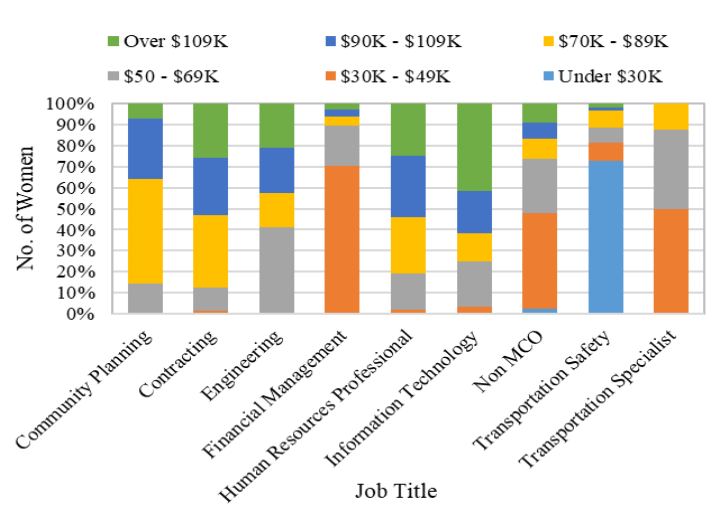

a. \# of female employees with different salaries in different job positions

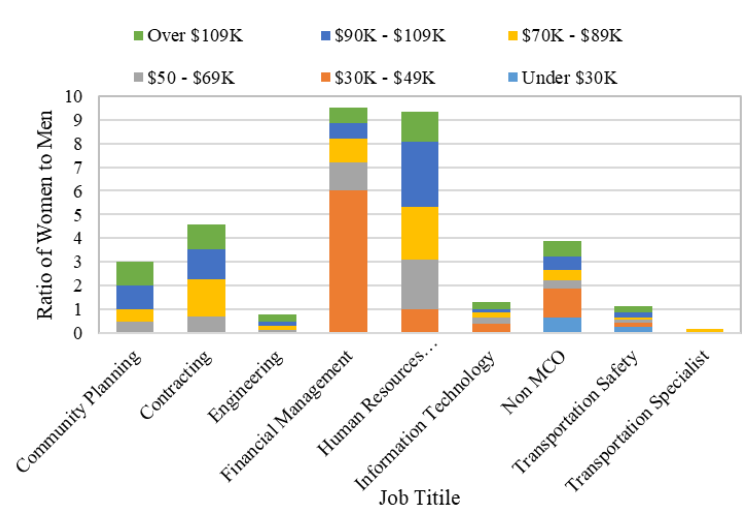

b. Female to male ratio with different salaries in different job positions

Fig. 8. Female representation with different salary ranges in different job positions at USDOT

\subsection{Women's education levels}

Fig. 9.a shows the number of employees based on their education level and shows that more employees, of both genders, had education levels of high school degree or less and bachelor's or post-bachelor's degree. Fig. 9.b shows the ratio of female to male employees in each education range and illustrates that the highest ratio was in the education level of graduate or professional degree (59\%), while the lowest ratio was in the education level of a high school degree or less (22\%). A likelihood-ratio test was used to test whether there is a statistically significant correlation between the female to male employee ratio and the education level (null hypothesis \#5). It resulted in a P-value of $<0.0001$, which rejects the null hypothesis. Therefore, there is statistical evidence to prove that women's representation has changed regarding the employee's education level. In general, it can be concluded that there is more women representation with higher levels of education. In other words, higher education can reduce women's underrepresentation.

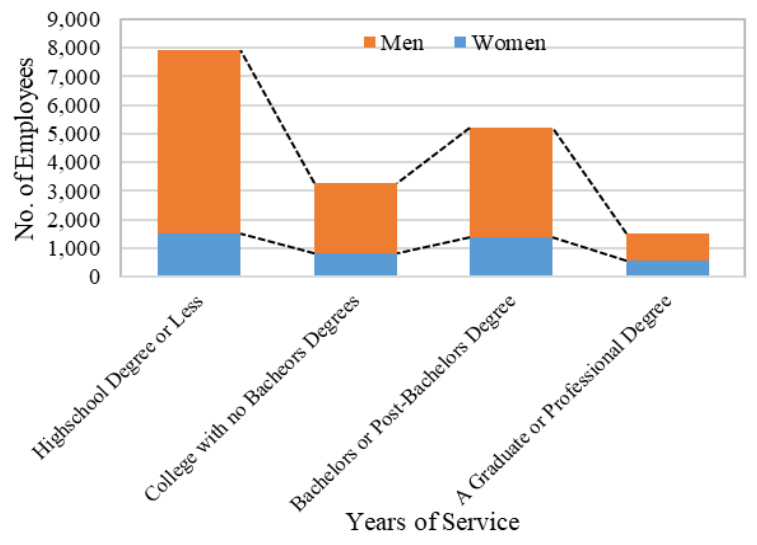

a. \# of employees with education level

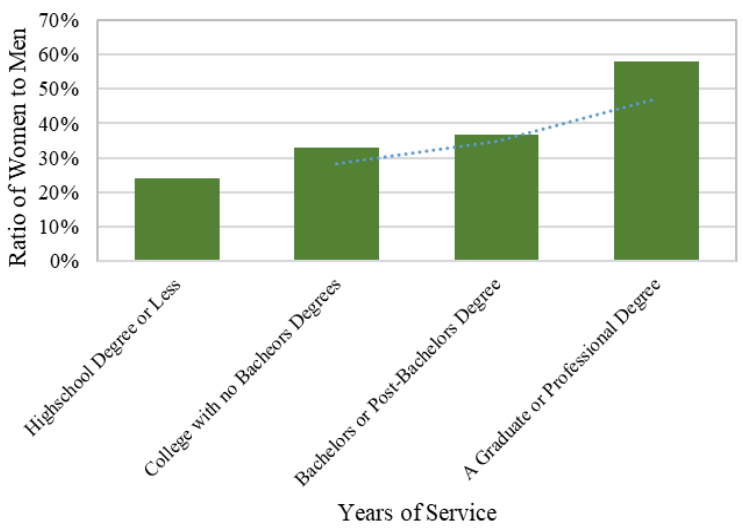

b. Female to male employees ratio with education

Fig. 9. Female representation in different education levels at USDOT

\subsection{Women's experience levels}

In this section, the experience level of female employees was explored at USDOT. Fig. 10.a shows the number of employees based on their experience range. The figure illustrates that, as was expected, there were more employees (both female and male) with a lower experience level. Fig. 10.b shows the ratio of female to male employees in each experience range. The highest ratio was in experience range of 20 to 24 years (61\%), while the lowest ratio was in the experience range of 5 to 9 years (24\%). A likelihood-ratio test was used to test whether there is a statistically significant correlation between the female to male employee ratio and the experience level (null hypothesis \#6). It resulted in a P-value of $<0.0001$, which rejects the null hypothesis. Therefore, women's representation has changed regarding the employee's experience range, and it can be concluded that there is higher representation of women in employees with higher levels of experience. 


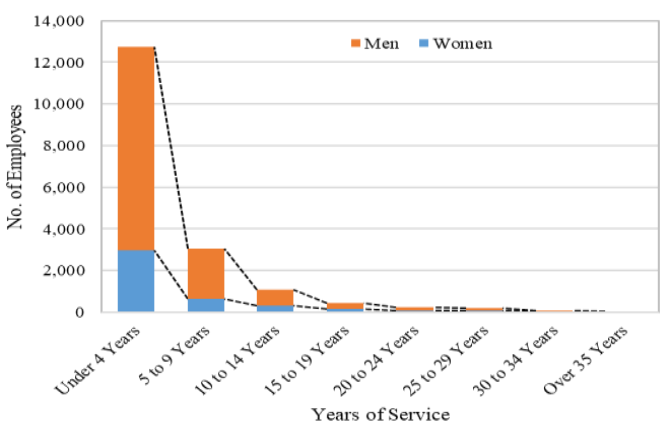

a. \# of employees with experience ranges

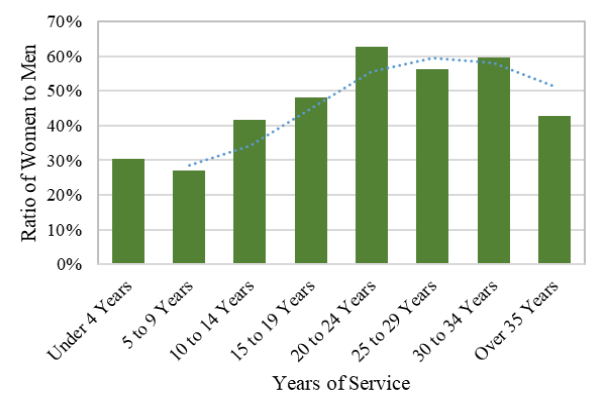

b. Female to male employees ratio with experience

Fig. 10. Female representation in different experience ranges at USDOT

The trend of the number of female employees and their proportion to male employees was explored for different job positions with different experience ranges at USDOT. Fig. 11.a shows the trend of female employees in each job position and each salary range, and illustrates that for most of the job positions (except human resource professional and contracting), the major level of experience for female employees was under 4 years.

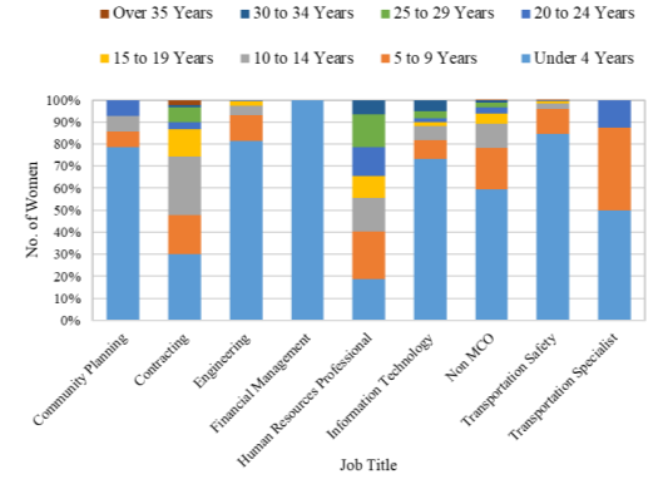

a. \# of females with different experiences in different job positions

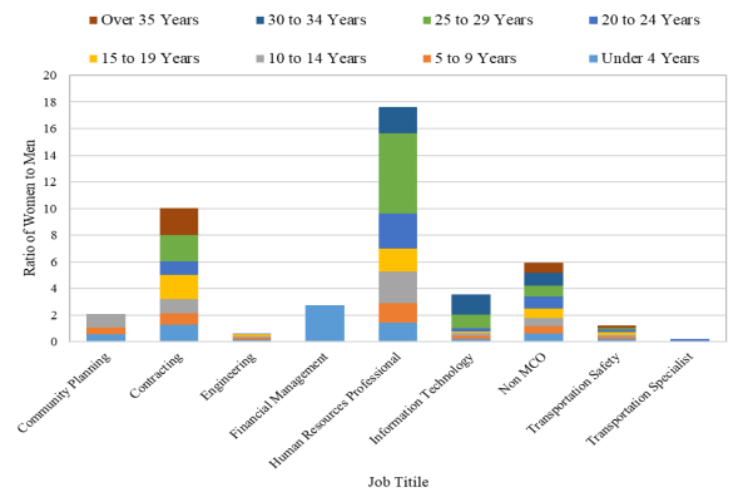

b. Female to male ratio with different experiences in different job positions

Fig. 11. Female representation with different experience levels in different job positions at USDOT

Fig. 11.b shows the ratio of female to male employees for each experience level and each job position. The trend of the number of female employees and their proportion to male employees was explored for different experience levels and salary ranges at USDOT. Fig. 12.a shows the trend of female employees for each experience level and in each salary range, and illustrates that more-experienced female employees usually had the higher-salaried jobs.

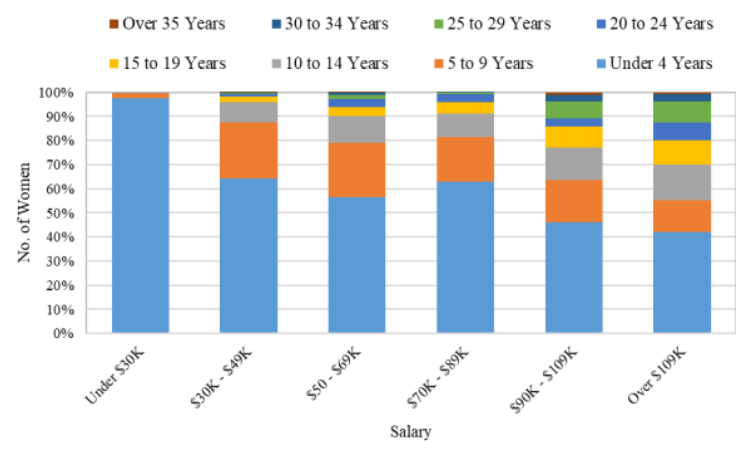

a. \# of females with different experience levels and salary ranges

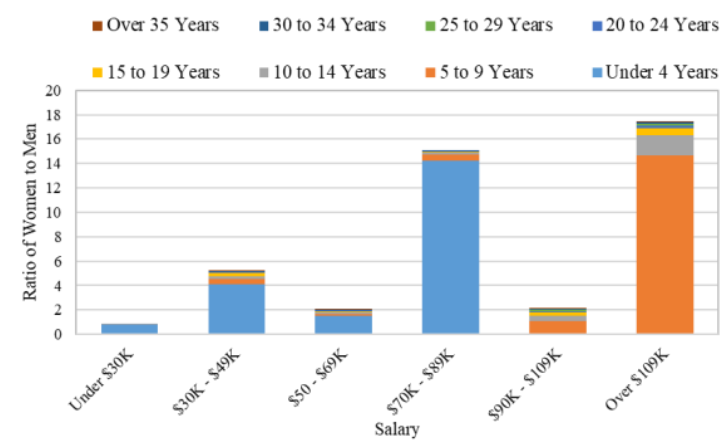

b. Female to male ratio with different experience levels and salary ranges

Fig. 12. Female representation with different experience levels and salary ranges at USDOT 
Fig. 12.b shows the ratio of female to male employees with different experience ranges and with different salaries, and illustrates that in all of the salary ranges, the positions that require a lower level of experience (under 4 years or 5 to 9 years) had the highest ratio of female to male employees.

\section{Conclusion}

Women are less represented than men in engineering fields. Within the last decades, there has been an increase in the number of females going into engineering, but there is still a gap between the representation of men and women. This has led to several socioeconomic issues that make it necessary to analyze the corresponding causal factors. In this study, the current underrepresentation of women in engineering was explored, and the factors that can decrease and/or eliminate this issue were discovered. Demographic data of the USDOT workforce from 2011 - 2017 was used to perform a descriptive analysis. The factors that impact gender representation and a wage gap were investigated, including job location, education level, type of appointment, job position and its importance, level of experience, and the supervisory role of the employees. The outputs showed that even though the females were underrepresented among the USDOT employees, there was no considerable wage inequality. It was found that women were mostly underrepresented in the higher level positions, and the most significant factor in reducing the inequity was a higher level of education. The results of this study can help public and private organizations and agencies design legislative initiatives to reduce the gender gap and achieve more gender equality. Furthermore, the study will help the workforce of any engineering organization to move toward a more gender diverse working environment, which will result in the reduction and/or elimination of gender inequality and its consequent challenges in their agencies.

\section{References}

[1] D.M., Domenico, K.H., Jones. "Career aspirations of women in the 20th century". Journal of career and technical education, V22 n2, 2006.

[2] S., Kermanshachi, and E. Safapour. "Assessing students' higher education performance in minority and non-minority serving universities". IEEE Frontiers in Education Conference (FIE), Indianapolis, IN, (2017) 1-6.

[3] M., Torre. "The scarring effect of "women's work": The determinants of women's attrition from male-dominated occupations". Social Forces, 93(1), 1-29, 2014. https://doi.org/10.1093/sf/sou059

[4] J. Weber. "Discrimination against Women in the Field of Engineering". Undergraduate Voices, (2018).

[5] D.A., Major, D.D., Donald, J. Sanchez-Hucles, J.D., Heather, L.M., Germano. "Myths and realities in the IT workplace: gender differences and similarities in climate perceptions." Women and minorities in science, technology, engineering, and mathematics: Upping the numbers, 2007. https://doi.org/10.4337/9781847206879.00012

[6] A.M., Beaton, F., Tougas, N., Rinfret, T., Monger. "The psychological disengagement model among women in science, engineering, and technology". British Journal of Social Psychology, 54(3), 465-482, 2015. https://doi.org/10.1111/bjso.12092

[7] J., Hunt. "Why do Women Leave Science and Engineering?". ILR Review, 69(1), 199-226, 2016. https://doi.org/10.1177/0019793915594597

[8] M., Infante-Perea, M., Román-Onsalo, E., Navarro-Astor. "Perceived career barriers for future female and male Spanish building engineers: Case of occupations related to work on site". Journal of Prof. Issues in Eng. Edu. and Prac., 142(4), 04016007, 2016. https://doi.org/10.1061/(asce)ei.1943-5541.0000286

[9] P.C., Charity-Leeke. "Women in engineering: a phenomenological analysis of sociocultural contextual meaning of gender roles". PhD dissertation, Cleveland State University, 2012.

[10] R.J., Burke, M.C., Mattis. "Women and Minorities in Science, Technology, Engineering and Mathematics; Upping the Numbers". Edward Elgar: Cheltenham, UK, 379pp, 2007. https://doi.org/10.1002/cjas.99

[11] N.L., Sulaiman, K., Mohd Salleh, M. M., Mohamad, C.S., Lai. "Technical and vocational education in Malaysia: policy, leadership, and professional growth on Malaysia women”. Asian Social Science, 11(24), 2015. https://doi.org/10.5539/ass.v11n24p153

[12] M., Kamro, Kesediaan menceburi kerjaya kejuruteraan binaan dalam kalangan pelajar jurusan binaan bangunan di Sekolah Menengah Vokasional. PhD dissertation. University of Tun Hussein Onn Malaysia, 2012.

[13] M., Christie, M., O'Neill, K., Rutter, G., Young, A., Medland. "Understanding why women are under-represented in science, technology, engineering and mathematics within higher education: a regional case study". Production, 27, e20162205, 2017. https://doi.org/10.1590/0103-6513.220516

[14] A., Fingleton, M., Loughnane, L., McGuinness, K., McKenna. "Towards Gender Balance in Engineering". Report, University College Dublin Engineering Graduates Association, 2014.

[15] H., Mishkin, N., Wangrowicz, D., Dorib, Y.J.,Dori. "Career choice of undergraduate engineering students". Procedia - Social and Behavioral Sciences, 222 - 228, 2016. https://doi.org/10.1016/j.sbspro.2016.07.033

[16] A., Jafari, B., Rouhanizadeh, S., Kermanshachi, and M., Murrieum. "A Predictive Analytics Approach to Evaluate Wage Inequality in Engineering Organizations". Journal of Management in Engineering, (In press), 2020.

[17] J.R., Steele, L., Reisz, A., Williams, K., Kawakami. "Women in mathematics: Examining the hidden barriers that gender stereotypes can impose. Women and minorities in science, technology, engineering, and mathematics", 159-183, 2007. https://doi.org/10.4337/9781847206879.00017

[18] E., Safapour, and S., Kermanshachi. "The Effectiveness of Engineering Workshops on Attracting Hispanic Female Students to Construction Career Paths". In Proceedings of the ASCE Construction Research Congress (CRC), Tempe, AZ, USA (Vol. 16), 2020.

[19] A., Eagly, W., Wood, A., Diekman. "Social role theory of sex differences and similarities: A current appraisal". In T. Eckes and H. M. Trautner (Eds.), The Developmental Social Psychology of Gender, 123-174, 2000 
[20] F., Galy-Badenas, "A qualitative study of male and female perceptions in differences in the working and domestic sphere: A comparison of the French and Finnish cultures". Master Thesis. University of Jyväskylä, Department of Communication, 2015.

[21] R.J., Burke. "Women and minorities in STEM: A primer". Women and minorities in sci., tech., eng. and math., 1, 3-27, 2007

[22] X., Wang, H.Y., Chan, S.J., Soffa, B.R., Nachman. "A nuanced look at women in STEM fields at two-year colleges: Factors that shape female students' transfer intent”. Frontiers in psychology, 8-146, 2017. https://doi.org/10.3389/fpsyg.2017.00146

[23] H.R., Karimian, B., Rouhanizadeh, A., Jafari, and S., Kermanshachi. "A Machine Learning Framework to Identify Employees at Risk of Wage Inequality: US Department of Transportation Case Study". In ASCE International Conference on Computing in Civil Engineering, 2019. https://doi.org/10.1061/9780784482438.004

[24] K., Zula. "The future of non-traditional occupations for women: A comprehensive review of the literature and implications for workplace learning and performance". Journal of Diversity Management, 9, 24-32, 2014. https://doi.org/10.19030/jdm.v9i1.8619

[25] S., Kermanshachi, and H. Sadatsafavi. "Predictive Modeling of US Transportation Workforce Diversity Trends: A Study of Human Capital Recruitment and Retention in Complex Environments". In Proceedings of ASCE International Conference on Transportation \& Development, Pittsburgh, PA, 2018. https://doi.org/10.1061/9780784481561.011

[26] B., Balamuralithara, S.L., Foon, M.N.A., Azman. "Persepsi pelajar perempuan terhadap program dan profesion dalam bidang kejuruteraan: Kajian kes di Malaysia dan". Jepun.. Jurnal Teknologi (Sciences \& Engineering), 72:1, 1-6, 2015. https://doi.org/10.11113/jt.v72.3217

[27] P., Mahajan, G., Suresh. "Engineering a woman: Marketing opportunities and challenges in India". American Journal of Management Science and Engineering, 2(1), 11-22., 2017

[28] S., Kermanshachi, K.K., Hyun, and E., Safapour. "Path to developing influential Hispanic leaders". Engineering Information Foundation (EIF), research report, 2019.

[29] J., Myers. "Why more women aren't becoming engineers". Globe and Mail, 2010.

[30] H., Foust-Cummings, L. Sabattini, N., Carter. "Women in Technology: Maximizing Talent, Minimizing Barriers". Catalyst Publication, 2008.

[31] M., Tapia, E., Safapour, S., Kermanshachi, and R. Akhavian. "Investigation of the barriers and their overcoming solutions to women's involvement in the US construction industry". In Proceedings of the ASCE Construction Research Congress (CRC), Tempe, AZ, USA (Vol. 16), 2020. 